\title{
Implementing Internet-Based Cognitive Behavioral Therapy in Routine Care: Healthcare Practitioners' Attitude and Perceived Level of Normalization After a Single Information Event
}

\author{
Anna-Lena Netter ${ }^{1}$ (I) $\cdot$ Anne Etzelmueller ${ }^{2,3} \cdot$ Tilo Kircher $^{4} \cdot$ Tim Rapley $^{5} \cdot$ David Daniel Ebert $^{2,3}$. \\ Eva-Lotta Brakemeier ${ }^{1,6}$
}

Received: 15 November 2020 / Revised: 29 October 2021 / Accepted: 10 December 2021 / Published online: 7 February 2022

(c) The Author(s) 2022

\begin{abstract}
Understanding implementation-related factors and processes is key to ensuring that Internet-based interventions are embedded in practice and provide added value to the delivery of evidence-based care. The aim of this study was to evaluate the attitudes towards an Internet-based cognitive behavioural therapy (iCBT) intervention for the treatment of depression as well as its level of normalization and early implementation success (operationalized as intention to use the intervention) among German health care professionals (HCP). Data were collected following onetime information sessions on an iCBT tool using the Evidence-Based Practice Attitude Scale (EBPAS) and the Normalization Process Theory Measure (NoMAD). Influences of attitudes on normalization as well as influences of attitude and normalization on intention to use were analysed. Most participants ( $n=78 ; 86.3 \%$ clinical psychologists, 9.6\% general practitioners) intended to use the intervention in the future $(82.1 \%)$ and had a moderately positive attitude towards iCBT interventions. The perceived level of normalization (i.e., the level of how well iCBT is integrated in practice) was moderate in the overall sample. High appeal, openness towards iCBT, low requirement to use it, and low perceived divergence (perceived difference between current and new practices) had a significant positive effect on normalization. This study indicates that iCBT can be implemented in German routine mental healthcare. However, implementation processes might benefit from tailored information campaigns that clearly highlight the effectiveness and benefits of iCBT interventions to foster openness towards iCBT interventions among HCPs.
\end{abstract}

Keywords Depression · Implementation · Normalization · Evidence-based practice · Attitudes · Internet-based interventions $\cdot$ Cognitive behavioural therapy $\cdot$ Routine care

\section{Introduction}

Addressing the demand for treatment of common mental health problems, such as major depressive disorder (MDD), is a severe public challenge. MDD is associated with significant impairment like the reduction in quality of life and mortality

Anne Etzelmueller and Anna-Lena Netter share the first authorship.

Anna-Lena Netter

anna-lena.netter@staff.uni-marburg.de

(Whiteford et al., 2015). Despite effective treatment options for

Anne Etzelmueller

anne.etzelmueller@tum.de

1 Department of Clinical Psychology and Psychotherapy, Philipps-University of Marburg, Marburg, Germany

2 GET.ON Institut für Online Gesundheitstrainings $\mathrm{GmbH}$, HelloBetter, Hamburg/Berlin, Germany

3 Department of Sport and Health Science, Technical University of Munich, Munich, Germany

4 Department of Psychiatry and Psychotherapy, Philipps-University Marburg, Marburg, Germany

5 Department of Social Work, Education and Community Wellbeing, Northumbria University, Newcastle upon Tyne, UK

6 Department of Clinical Psychology and Psychotherapy, University of Greifswald, Greifswald, Germany 
MDD, most individuals affected remain untreated (Mack et al., 2014; Thornicroft et al., 2017). Long waiting periods for therapy due to the lack or uneven distribution of trained providers, dependency on location and time, or the complexity and chronicity of patient's symptomatology are frequent barriers to treatment access (Mack et al., 2014; Wittchen et al., 2011). Additionally, attitudinal barriers such as low perceived need, low mental health literacy, financial factors, and fear of stigmatization towards mental illness prevent people from seeking help and receiving treatment (Schnyder et al., 2017).

Providing Internet-based treatments may be one way to reduce barriers and increase access to mental health care (Ebert et al., 2018). Potential benefits of internet-based treatments include the ability to reach a wide range of individuals affected, easy accessibility, and cost-effectiveness (Andersson et al., 2019). Most Internet-based programs developed and evaluated for mental health include different forms of cognitive behavioural therapy (CBT), also referred to as iCBT. iCBT has proven to be effective for the treatment of a wide range of mental disorders compared to non-treated controls (Ebert et al., 2018), including depression (Karyotaki et al., 2018; Königbauer et al., 2017; Zachariae et al., 2015). A meta-analysis on therapeutically guided iCBT shows comparable efficacy with face-to-face treatments for depression in adults (Carlbring et al., 2018). In addition, iCBT for the treatment of depression and anxiety has shown to be effective when implemented in routine mental health care (Etzelmueller et al., 2020).

Although potentially useful interventions have been developed and research on these interventions has been very promising so far, it is still an enormous challenge to transcend. ICBT needs to become part of routine practice, implemented in a variety of settings. Factors at the contextual, organizational, and individual levels influence the implementation of evidence-based interventions (Aarons et al., 2012a; Raghavan et al., 2008). Additionally, a poorly implemented intervention may lead to a negatively perceived effectiveness of that intervention even if in reality it is a failed implementation process or a contextual mismatch leading to a worse outcome (Aarons \& Palinkas, 2007). While most research on iCBT has focused on effectiveness and efficacy, implementation processes of such interventions have rarely been addressed (Drozd et al., 2016). Understanding the processes and work involved in implementing complex interventions, including iCBT interventions, is key to the sustainable integration of innovation into the context of routine care and might form a bridge between research and practice.

The normalization process theory (NPT) provides a theory for understanding relevant processes and work that needs to be done to implement an intervention and can be used to understand the dynamics of implementing new practices or interventions in routine health care (May \& Finch, 2009). The theory focuses on the "work that individuals and groups do to enable an intervention to become normalized" (Murray et al., 2010, p. 2). NPT postulates that "practices become routinely embedded in social contexts ('normalized') as the result of people working, individually and collectively, to enact them" (Finch et al., 2013, p. 2). NPT posits four processes relevant to the normalization of a newly implemented practice: (a) sense-making that promotes or inhibits the coherence of a practice to its users; do people see potential value and worth in iCBT?; (b) cognitive participation that promotes or inhibits users' enrolment and legitimization of a practice; do people commit to using iCBT?; (c) collective action that promotes or inhibits the enacting of a practice by its users; do people individually and collectively invest effort into using iCBT?; and (d) reflexive monitoring that promotes or inhibits users' comprehension of the effects of a practice; do people invest in the appraisal of the iCBT service. Previous studies underpin the ability of the theory to explain change processes in complex systems including a multiple stakeholder perspective (May et al., 2018).

Healthcare professionals (HCPs) are particularly important stakeholders in terms of implementation, as they not only provide treatment recommendations to patients and usually carry out the treatments but also mediate patients' attitudes towards specific treatment approaches (Gun et al., 2011). In implementing iCBT interventions, characteristics of individual practitioners (e.g. education, training, beliefs, personality) are brought into the equation of an already complex context of mental health services. The individual attitude of HCPs towards iCBT in general, in line with their willingness to change to integrate iCBT into their treatment programs, is an important component of implementation readiness (Aarons et al., 2012b) and could therefore be an important complement to NPT. A better understanding of practitioners' attitudes towards (the adoption of) mental health interventions could enhance the implementation process by making interventions more tailored to their needs (Aarons et al., 2010).

Based on the literature, Aarons (2004) postulate four relevant domains of practitioner's attitudes towards evidencebased interventions such as iCBT: (a) the intuitive Appeal of evidence-based interventions; do people intend to use iCBT based on its appeal?; (b) the likelihood of adopting interventions given organizational Requirements; do people use iCBT when they are required to?; (c) Openness to innovation; are people willing to try new interventions like iCBT?; (d) and perceived Divergence between research-based interventions and the usual practice; do people experience iCBT as useful? Especially in early implementation stages and in HCPs without any previous iCBT experience, a negative attitude towards iCBT can be a cause for low uptake. A better understanding of attitudes towards the new intervention could help to improve implementation and therefore support normalization and early implementation success. Associations between HCPs' attitudes and NPT have not yet been 
investigated, despite a growing number of studies using NPT to monitor implementation processes.

In early implementation stages (e.g. directly after an information session), it is often difficult to measure implementation success directly. The unified theory of acceptance and use of technology (UTAUT) is a well-established theoretical model used to study user acceptance and its barriers and facilitators in new technologies, such as iCBT (Venkatesh et al., 2003). It assumes that the intention to use an intervention predicts the actual use of the intervention (Khechine et al., 2016). Intention thus seems to be well suited to get a first impression of implementation success. Also, knowledge of associations between HCPs' attitudes, normalization, and implementation success at an early stage of implementation could further help optimize and adapt implementation strategies to the specific needs of stakeholders.

\section{Study Goals}

The aim of this study was to evaluate implementation-related factors and early implementation success (operationalized by intention to use the intervention) among German HCPs in an early phase of iCBT implementation. Theory-based individual and contextual factors were addressed to be able to assess the readiness for implementation. Specific objectives for this study were to (1) evaluate HCPs' general attitude towards iCBT and their perceived level of normalization and intention to use the introduced iCBT tool, (2) to analyse the influence of HCPs' attitudes towards iCBT on normalization, and (3) to explore influences of attitude and normalization on intention to use. The evaluation of such aspects prior to the more specific implementation work with the goal of developing an implementation plan and concrete implementation activities are thought to enhance the investment, uptake, and sustainment of the services.

\section{Methods}

\section{Study Design}

A longitudinal study with repeated measure design with three measurement points (immediately after information session, after 3 months, after 6 months) was adopted to assess relevant implementation factors and implementation process in German HCPs via self-administered surveys. The actual use of the tool or further barriers that prevent its use were to be investigated by means of the second and a third measurement point. Due to a high dropout rate $(78.2 \%)$, only data from the first measurement point will be reported in the following. Consequently, the third survey had to be cancelled.

The survey of the data presented here was conducted following initial onetime information sessions on the webbased self-management tool "iFightDepression" (iFD), which can be applied as a supplement to regular depression treatment or to bridge the waiting period. Psychotherapists and general practitioners were invited to the sessions. Normalization and attitudes towards new interventions were operationalized by empirically validated constructs and questionnaires. Detailed verbal and written information on the study was provided following the information session. Only participants who gave their written consent were included in the study. The study was carried out in compliance with the regulations and guidelines established by the German Society for Psychology.

\section{Participants and Recruitment}

Recruitment was administered in person (by the authors A.L.N. and E.L.B. from February 2018 to November 2018) directly after onetime information sessions organized by the local non-profit association "Alliance against depression Marburg-Biedenkopf". The association carried out the implementation of iFD in the area through several one-time information sessions. A total of six information sessions were conducted as part of staff meetings in local psychosomatic or psychiatric clinics $(n=3)$, in monthly meetings of professional groups $(n=2)$, or by inviting general practitioners and psychotherapists via e-mail to a separate information event held by the association $(n=1)$. All information sessions included a 20-min presentation with information on the general effectiveness of iCBT, a short insight into the iFD tool in the form of screenshots, information on the online training for HCPs, potential areas of application of the tool in depressed patients, and a concluding question and answer session. All information sessions were held exclusively by author T.K., who was not involved in data collection and analyses.

\section{Intervention}

The iFD tool (www.ifightdepression.com/en/) is an evidence-based tool rooted in the principles of CBT (Arensman et al., 2015; Oehler et al., 2020). The tool includes six weekly online workshops on specific topics regarding depressive symptoms (1. Thinking, feeling, and doing, 2. Sleep and depression, 3. Planning and doing enjoyable things, 4 . Getting things done, 5. Identifying negative thoughts, 6. Changing negative thoughts), including written information, worksheets, exercises, and a mood rating (Oehler et al., 2019). Within the context of the introduction 
by the local association, iFD was planned to be implemented as a guided intervention. In this context, referrers to this program were expected to work as "guides", identifying patients, and providing access to the tool in the context of the treatment, while continuing their regular treatment. As guides, HCPs answer patients' questions and motivate them to use the tool. HCPs were not presented with any incentives to use the tool and there was no requirement imposed on them to use the tool by their organization or superior.

\section{Measures}

The survey consisted of sections on demographics, background information on the participants' treatment of depression. Furthermore, we included measures to assess the respondents' attitude towards iCBT (EBPAS, Aarons et al., 2010) and the degree of normalization of the intervention (NoMAD questionnaire, Finch et al., 2018; Rapley et al., 2018) as well as their intention to use the tool (measuring early implementation success).

Demographic information included age, gender, duration of employment, current occupation, and previous experience with iCBT. Additional items assessed background information on the HCP's routine work (including proportion of depressed patients, applied treatment for depression, proportion of depressed patients eligible to use the iCBT intervention, and previous experience with the iCBT intervention). Based on UTAUT (Venkatesh et al., 2003) the participants' intention to use the intervention after the information session was operationalized by the question "How likely is it that you are going to use the intervention?" answered on a six-point Likert scale.

\section{Attitude Towards New Practices (EBPAS)}

Attitudes were measured with the 15 -item version of the Evidence-based Practice Attitude Scale (EBPAS; Aarons, 2004). This well-established measure includes the scales (a) intuitive Appeal (4 items), (b) Requirements (3 items), (c) Openness to change (4 items), and (d) Divergence (4 items). The EBPAS total score measures practitioners' attitudes towards implementing the intervention (Aarons, 2004), where a higher mean score indicates a more favourable attitude. The questionnaire is answered on a 5-point Likert scale $(0=$ not at all to $4=$ to a very great extent $)$. The EBPAS provides a clear factor structure, adequate internal consistency for the total score $(\alpha=0.79-0.77)$ and good internal consistency for the subscale scores $(\alpha=0.93-0.74)$, except for the divergence scale ranging somewhat weaker across studies ( $\alpha=0.66-0.56$; Aarons et al., 2007, 2010; van Sonsbeek et al., 2015). For the present study, a German translation of the questionnaire was used (Frantz \& Heinrichs, 2015).

\section{Normalization Process Theory Measure (NoMAD)}

The NoMAD (Finch et al., 2018) is based on NPT to assess and monitor the implementation process from a HCP's perspective. The development of the questionnaire which included consensus workshops, interviews, appraisal of item quality, and expert rating is described in detail elsewhere (Rapley et al., 2018). The NoMAD consists of three sections: section A assesses general information on the participant, section B includes three general items on the intervention answered on an 11-point Likert scale ranging from 0 to 10 with descriptive anchors at 0,5 and 10 ((1) "How familiar does iFD feel for you?"; (2) "Do you feel that iFD is currently a normal part of your work?"; (3) "Do you feel that iFD will become a normal part of your work?"). Section C) contains 20 items representing the four key constructs of NPT: coherence (4 items), cognitive participation (4 items), collective action ( 7 items), and reflexive monitoring (5 items). Section $\mathrm{C}$ items are answered on a 5 -point Likert scale $(1=$ strongly agree; $5=$ strongly disagree). The NoMAD shows a clear factor structure and a strong internal consistency supporting a general normalization measure (20 items, Cronbach's $\alpha=0.89$ ) as well as calculation of four subscales (Cronbach's $\alpha$ ranging from 0.65 to 0.81 ; Finch et al., 2018). The forward-backward translated German version of the NoMAD was used in this study (The ImpleMentAll Project, 2020). As recommended by the developers, the NoMAD had been slightly modified to make it useful for this specific context (Finch et al., 2018). The Cronbach's $\alpha$ in these data was $\alpha=0.85$ for the NoMAD and $\alpha=0.76$ for the EBPAS, respectively.

\section{Procedure}

Directly after the information sessions, all attendees were invited to participate in the study. After providing oral and written study information and written consent, the survey was carried out directly on-site using a paper-pencil questionnaire. Due to a low response rate, data from the second and third measurement points cannot be analysed and presented here.

\section{Statistical Analysis}

Participants' characteristics were analysed using descriptive statistics, as are the participants' attitudes, their degree of normalization, and their intention to use. We re-coded the NoMAD items so that a higher value would indicate a higher level of normalization. We also re-coded the EBPAS subconstruct Divergence, so that on all four constructs a higher score indicates a more positive attitude towards 
the intervention. Furthermore, we evaluated the prediction of normalization from EBPAS' subconstructs Appeal, Requirements, Openness and Divergence, and the NoMAD subconstructs Coherence, Cognitive participation, Collective action, and Reflexive monitoring, respectively, using regression analysis. We also evaluated the prediction of the "intention to use" the iCBT tool from EBPAS and NoMAD constructs.

$\mathrm{R}$ version 3.5.3 ( $\mathrm{R}$ Core Team, 2019) was used for all analyses.

\section{Results}

\section{Study Demographics}

Table 1 provides an overview of the demographic characteristics of the sample. In total, 78 participants completed the questionnaire. The mean age was 43.42 years, $(S D=13.64$; range 23-68), the gender distribution was balanced (48.7\% female). The vast majority worked as psychotherapists (86\%), $10 \%$ as general practitioners. Of all participants, $22 \%$ had been working at their current workplace for less than a year, 29\% for more than 15 years. All participants reported treating depressed patients, mainly with CBT treatment $(85 \%)$, none with iCBT.

\section{Participants' Intention to Use the iCBT Tool}

Participants stated to be convinced of the intervention after the information session indicating that they are "very likely" (16.7\%), "likely" (28.2\%), or "rather likely" (37.2\%) to use the tool. Their intention to use the tool with patients $(\mathrm{M}=2.65, S D=1.16)$ can be seen as likely. Of all participants, $87.2 \%$ would also recommend the use of the tool to a colleague.
Table 1 Sociodemographic characteristic of the sample $(n=78)$

\begin{tabular}{|c|c|}
\hline Characteristics & $N=78$ \\
\hline Age, years M $(S D)$ & $43.42(13.64)$ \\
\hline Gender, female, $n(\%)$ & $37(48.7 \%)$ \\
\hline \multicolumn{2}{|l|}{ Occupation, $n(\%)$} \\
\hline Psychotherapist & $63(86.3)$ \\
\hline General practitioner & $7(9.6)$ \\
\hline Referrer & $1(1.4)$ \\
\hline Nurse & $2(2.7)$ \\
\hline \multicolumn{2}{|l|}{ Duration of employment in current workplace, $n(\%)$} \\
\hline Less than 1 year & $17(22.1)$ \\
\hline $1-2$ years & 12(15.6) \\
\hline $3-5$ years & $11(14.3)$ \\
\hline $6-10$ years & $11(14.3)$ \\
\hline $11-15$ years & $4(5.2)$ \\
\hline More than 15 years & $22(28.6)$ \\
\hline \multicolumn{2}{|l|}{ Percentage of depressed patients in care of HCP, $n(\%)$} \\
\hline$<10 \%$ & $1(1.3)$ \\
\hline $10-30 \%$ & $27(34.6)$ \\
\hline $30-50 \%$ & $24(30.8)$ \\
\hline $50-70 \%$ & $20(25.6)$ \\
\hline $70-100 \%$ & $5(6.4)$ \\
\hline \multicolumn{2}{|l|}{ Applied treatments for depression, $n(\%)$} \\
\hline Mainly CBT (including 3rd wave interventions ${ }^{\mathrm{a}}$ ) & $66(84.6)$ \\
\hline Mainly psychodynamics & $4(5.1)$ \\
\hline Mainly pharmaceutical treatment & $8(10.3)$ \\
\hline \multicolumn{2}{|c|}{ HCPs including 3rd wave interventions into treatment, $n(\%)$} \\
\hline Yes & $20(25.6)$ \\
\hline No & $58(74.4)$ \\
\hline
\end{tabular}

Third wave intervention meaning modern CBT techniques such as dialectical behavioural therapy (DBT), acceptance and commitment therapy (ACT), or cognitive behavioral analysis system of psychotherapy (CBASP) 
Table 2 HCPs' attitude and level of normalization after information session $(n=78)$

\begin{tabular}{ll}
\hline Outcome & $\mathrm{M}(S D)$ \\
\hline EBPAS total & $2.19(0.39)$ \\
EBPAS organizational requirements & $2.00(1.07)$ \\
EBPAS intuitive appeal & $2.84(0.59)$ \\
EBPAS openness & $2.73(0.71)$ \\
EBPAS divergence & $2.87(0.70)$ \\
NOMAD mean & $3.38(0.44)$ \\
NOMAD coherence & $3.33(0.53)$ \\
NOMAD cognitive participation & $3.45(0.70)$ \\
NOMAD collective action & $3.22(0.44)$ \\
NOMAD reflective monitoring & $3.44(0.51)$ \\
NOMAD General item 1 & $2.53(2.18)$ \\
NOMAD General item 2 & $1.49(2.18)$ \\
NOMAD General item 3 & $5.38(1.98)$ \\
\hline
\end{tabular}

Normalization process theory measure (NOMAD; possible range from 1 to 5, with higher scores indicating a higher level of normalization)

Attitude towards new practices (EBPAS; possible range from 0 to 4, with higher scores indicating more favourable attitudes)

General "normalization" items (possible from range 0-10, higher scores indicating higher approval)

\section{HCPs' Attitude Towards New Practices and Level of Normalization}

The mean of the EPBAS total score was $2.19(S D=0.39)$, with the EPBAS constructs' means ranging from 2.00 $(S D=1.07)$ for Requirements and $2.87(S D=0.70)$ for Divergence (score has been reversed, meaning higher score lower Divergence). The mean of the NoMAD total score was $3.38(S D=0.44)$, with the NoMAD constructs' means ranging from $3.22(S D=0.44)$ for collective action and $3.45(S D=0.70)$ for cognitive participation. The means for the general normalization items were $2.53(S D=2.18)$

Table 3 Regression results using the NoMAD mean score as the criterion

\begin{tabular}{|c|c|c|c|c|c|}
\hline Predictor & $b$ & $\begin{array}{l}b \\
95 \% \text { CI } \\
{[\mathrm{LL}, \mathrm{UL}]}\end{array}$ & $S E$ & $t$ & $p$ \\
\hline $\begin{array}{l}\text { EBPAS organiza- } \\
\text { tional require- } \\
\text { ments }\end{array}$ & -0.06 & {$[-0.12,-0.01]$} & 0.03 & -2.33 & .023 \\
\hline $\begin{array}{l}\text { EBPAS intuitive } \\
\text { appeal }\end{array}$ & 0.11 & {$[0.01,0.22]$} & 0.05 & 2.12 & .037 \\
\hline EBPAS openness & 0.13 & {$[0.04,0.21]$} & 0.04 & 2.84 & .006 \\
\hline EBPAS divergence & 0.47 & {$[0.37,0.57]$} & 0.05 & 9.30 & $<.001$ \\
\hline
\end{tabular}

$R^{2}=0.636$; adjusted $R^{2}=0.615$. LL and UL indicate the lower and upper limits of a confidence interval CI, respectively for the question on familiarity with the intervention, 1.49 $(S D=2.18)$ for the current normalization of the intervention, and $5.38(S D=1.98)$ for the opinion on if the intervention will become a normal part of the work. Overview of all EBPAS and NoMAD subscales is presented in Table 2.

\section{Influences of Attitudes on the Level of Normalization}

Table 3 shows regression results using NoMAD mean score as the criterion and the EBPAS constructs as independent variables. The EBPAS constructs Divergence $(p<.001$, $\beta=0.469, S E=0.050, t=9.30, p<.001)$, Openness $(p<.01$, $\beta=0.125, S E=0.044, t=2.84, p=.006)$, as well as Requirements and Appeal $(p<.05$ level, $\beta=-0.065, S E=0.028$, $t=-2.33, p=.023$ and $\beta=0.112, S E=0.053, t=2.13$, $p=.037$ ) were found to have a significant positive effect on the NoMAD mean score.

Furthermore, the EBPAS construct Divergence was found to have a significant positive effect on the NoMAD Global Item 1 ("familiarity with the intervention"; $p<.01$ level, $\beta=1.277, S E=0.409, t=3.125, p=.003$ ) as well as on NoMAD Global Item 2 ("current normalization of the intervention"; $p<.05$ level, $\beta=1.002, S E=0.422, t=2.378$, $p=.020$ ) and NoMAD Global Item 3 ("opinion on if the intervention will become a normal part of the work"; $p<.01$ level, $\beta=1.016, S E=0.353, t=2.882, p=.005$ ).

Additionally, the EBPAS construct Appeal was found to have a significant effect on the NoMAD Global Item 3 ("opinion on if the intervention will become a normal part of the work"; $p<.05$ level, $\beta=0.779, S E=0.373, t=2.089$, $p=.40$ ). No other EBPAS constructs had an influence on any of the NoMAD Global Items.

The EBPAS construct Divergence was found to have a positive effect on the NoMAD construct Coherence ( $p<.001$ level, $\beta=0.688, S E=0.060, t=11.525, p<.001)$. The EBPAS constructs Openness and Divergence had a significant positive effect on the NoMAD construct Collective Action $(p<.001$ level, $\beta=0.255, S E=0.063, t=4.039$, $p<.001$ and $p<.05$ level, $\beta=0.173, S E=0.072, t=2.401$, $p=.018$, respectively). Also, the EBPAS construct Divergence was found to have a positive effect on the NoMAD construct Reflexive monitoring $(p<.001$ level, $\beta=0.381$, $S E=0.089, t=4.301, p<.001)$.

All regression results are depicted in Table 3 and the appendix (Tables 4, 5, 6, 7, 8, 9, 10, 11).

\section{Influences of Attitudes and Normalization on the Intention to Use the Intervention}

In an exploratory analysis, we investigated the influence of attitudes and normalization on the intention to use the intervention. 
There was no significant effect of the EBPAS total score on the intention to use the intervention $(\beta=-0.495, S E=0.337$, $t=-1.467, p=.146)$. The EBPAS constructs Requirements ( $p<.01$ level, $\beta=0.292, S E=0.102, t=2.860, p=.006)$, as well as Appeal and Divergence $(p<.001$ level, $\beta=-0.781$, $S E=0.193, t=-4.042, p<.001$ and $\beta=-0.694, S E=0.185$, $t=-3.760, p<.001$, respectively) were found to have a positive effect on the intention to use the intervention. The NoMAD mean score $(p<.001$ level, $\beta=-1.715, S E=0.258$, $t=-6.656, p<.001)$ and the and the NoMAD construct $C o g$ nitive participation ( $p<.001$ level, $\beta=-0.891, S E=0.190$, $t=-4.690, p<.001$ ) had a significant effect on the intention to use the intervention.

\section{Discussion}

The present study investigated an early-stage implementation of iCBT in routine care through different individual and contextual factors after a brief information session on the iCBT tool. Participants had a rather positive general attitude towards iCBT. At this early stage of implementation, the general normalization level was moderate. Attitudes as an overall construct and its subconstructs Divergence, Openness, Requirement, and Appeal predicted normalization. HCPs' intention to use the tool was high, considering an early implementation stage. A higher level of normalization was positively associated with HCPs intention to use the tool. While the EBPAS global score was not associated with the intention to use the tool, there was a positive association between the perceived appeal and low requirements and HPCs' intention to use the tool. Because of the small, nonrepresentative sample of HCPs, all study findings should be understood as initial indications that should now be further examined.

HCPs indicated a rather positive general attitude (EBPAS total) towards iCBT interventions, with a slightly lower mean approval $(\mathrm{M}=2.12$ vs. $\mathrm{M}=2.33)$ than reported in a US normative sample (Aarons et al., 2010, $n=1089$ ). The subscales Appeal $(\mathrm{M}=2.84$ vs. $\mathrm{M}=2.91)$, Openness ( $\mathrm{M}=2.73$ vs. 2.76$)$, and Divergence $(\mathrm{M}=2.87$ vs. $\mathrm{M}=2.75$ (reversed)) were close to the established norms. These results indicate an openmindedness of the HCPs in this study about iCBT which they found to be intuitively appealing. They also considered iCBT clinically useful and important. Scores of the subscale Requirement were lower than the norms ( $\mathrm{M}=2.00 \mathrm{vs.} \mathrm{M}=2.41)$, indicating that HCPs in this study prefer autonomy. If they can make their own decisions rather than getting requirements for using iCBT from a supervisor, their institution, or the federal government, they are more likely to embed it in their daily work.

Immediately after the information session on the iCBT tool, the level of perceived normalization was moderate. As none of the participants of the study were using the iCBT tool or had experience with it, the reported overall level of normalization can be considered relatively high. HCPs may not have felt familiar with the iCBT tool immediately after the information session and may not have considered it as a normal part of their work but saw its potential. The mean scores on the subconstructs Coherence and Cognitive Participation indicate that participants felt that iCBT might be a "good idea" and it felt like they should be involved, but they still had questions around how well they could use it in practice. The findings on normalization are comparable to those of a Dutch sample of practitioners also being involved in an early stage of different e-mental health implementation projects (Vis et al., 2019, $n=262$ ). Participants in this study showed a similar level of normalization (NoMAD mean score $)$ as the Dutch sample $(\mathrm{M}=3.38$ vs. $\mathrm{M}=3.54)$. The subscales Coherence $(\mathrm{M}=3.33$ vs. $\mathrm{M}=3.70)$ and Cognitive Participation ( $\mathrm{M}=3.45$ vs. $\mathrm{M}=3.69)$ were slightly lower. $\mathrm{Col}$ lective Action ( $\mathrm{M}=3.22$ vs. $\mathrm{M}=3.30)$ and Reflective Monitoring $(M=3.44$ vs. $M=3.55)$ are comparable. The sample characteristics of Vis and colleagues' study are comparable to the data presented here. The weighting of the different NPT constructs will vary depending on the intervention, the context and setting in which it is to be implemented as well as the individuals involved and their characteristics (Finch et al., 2018; McEvoy et al., 2014). To our knowledge, this present study is the first to examine potentially relevant factors influencing normalization in the early implementation of iCBT in Germany.

HCPs' general attitude towards new interventions such as iCBT play an important role regarding implementation readiness (Aarons et al., 2012b) and therefore might also be relevant when it comes to normalizing iCBT interventions in routine practice. No direct influence of HCPs' general attitude on the normalization level was found. However, a closer look at the subscales reveals how certain components of attitude do influence normalization. HCPs who find iCBT generally appealing show a higher level of normalization, indicating the importance of ensuring that the intervention is appealing to the target group from the very first steps of implementation. The EBPAS subscale Appeal is conceptually closely related to the NoMAD constructs. Also, HCPs who are open towards iCBT show higher levels of normalization and Collective Action. It can be assumed that workability, a focus within the concept of Collective Action, is a prerequisite for Openness. Encouraging HCPs' interest in and openness towards iCBT might therefore lead to a better chance to try new interventions (and thereby discovering workability and increasing the aspects concerning Collective Acting), be adaptive, and to finds ways of interacting with innovative practices. It was also found that a low perceived Divergence has a positive effect on the normalization level, Coherence, Collective Action, and Reflective Monitoring. Due to the low internal consistency of the Divergence scale (Aarons et al., 2007, 2010; van Sonsbeek et al., 2015), the results can only be considered with limitations. Although HCPs experience with iCBT was limited (none of the participants used iCBT in the treatment of depression) and previous studies identified a lack 
of experience with iCBT as an obstructive factor in its implementation (Drozd et al., 2016; Titzler et al., 2018), HCPs tended to think iCBT was useful. Information sessions or workshops that allow participants to gain more detailed impressions, could further reduce uncertainties. Acceptance-facilitating interventions, which introduce iCBT through a short video, have proven to be effective with psychotherapists and patients (Baumeister et al., 2020; Ebert et al., 2015). Adapting information to foster curiosity, and interest in novel interventions (e.g. to learn how iCBT can fill treatment gaps, how it can be applied, and how it is of relevance in clinical practice), maybe a good approach to improve HCPs' attitude towards iCBT. In this way, it could support Coherence and foster continuous use, enrolment, and integration into existing practices. In fact, previous studies have shown that support of HCPs significantly enhances successful implementation (Titov et al., 2019; Titzler et al., 2018). Mandatory use (e.g. by superiors, the own institution, or the government) seems to be an obstacle to normalizing the iCBT tool. Initial and ongoing training and supervision of HCPs, as well as adequate funding and technical support while maintaining the autonomy to make clinically informed decisions about when, with whom, and how iCBT is used appear to be important pillars (Titzler et al., 2018).

According to the UTAUT (Venkatesh et al., 2003), intention to use predicts actual use ( $r=0.46$, Khechine et al., 2016). After the information session, the HCPs in this study stated that they considered their intention to use the tool as high. Furthermore, a high intention to use was associated with a high level of normalization. Particularly strong correlations were found with Cognitive Participation, which may be due to the overlap of these constructs. HCPs who are willing to promote the use of the intervention through their own participation and commitment are certainly more likely to intend to use the intervention. Participants who rated the intervention as appealing and considered it clinically useful were also more likely to intend to use it. Aarons et al. (2010) stated that independent decision-making seems to be important when it comes to utilizing new interventions. Being required to use the intervention, e.g. by a supervisor or the institution, negatively affected the intention of the HCPs in this study to use the intervention. Self-determination, therefore, seems to be favourable for successful implementation.

The present overall findings indicate that HCPs might actually use the tool. However, the high dropout rates $(78 \%)$ in the follow-up measurement could indicate rather low actual usage. Initial information events might be a promising starting point for the HCPs' intention to use the tool, but they cannot guarantee actual use. Continued support of HCPs and their institutions (e.g. in-person guidance, technical support, continued study information), as well as incentives for use, could therefore be appropriate to lower dropout rates in study participation and maintain long-term implementation success (Terpstra et al., 2018; Titov et al., 2019) and transform initial interest into embedded and sustained use. Since the first measurement point occurred anonymously during information sessions via paper-pencil, participants could not be reminded in person, so it was difficult to reach people again after a session. Comparatively, low participation rates are a common challenge in many studies which included HCPs (Raftery et al., 2009).

\section{Limitations}

Several limitations should be considered when interpreting the present findings. First, the investigated implementation took place in a specific region in Germany. This circumstance set a natural limit for the participants in the current study, resulting in a relatively small sample size and a lack of a control condition. This study's findings should therefore be interpreted with caution and must be replicated in other regions and contexts.

Secondly, there are some methodological limitations. All additional data (e.g. on HCPs' background, their intention to use) were assessed using a non-validated single-item measure that was adapted to the specific context of the present study. Likewise, the applied German version of the EBPAS questionnaire is not psychometrically validated. Limitations in the interpretability of the Divergence subscale due to its low internal consistency must be considered (Aarons et al., 2010; Santesson et al., 2020; van Sonsbeek et al., 2015). In addition, recruitment was not carried out systematically but in a naturalistic setting. Some HCPs participated on their own initiative, while others came, for example, at the suggestion of superiors or institutions. This may have influenced the motivation of the HCPs involved. However, the naturalistic context of this study may allow a transfer to other similar implementation projects, which can adapt their strategies based on the present results.

In addition, it must be mentioned that the short information session that took place before the data collection was the first step in introducing the tool. None of the participants had any previous experience with the iCBT tool presented. Only after the information session, it was possible to begin to form an opinion about the tool and its possible use. At the same time, it must be assumed that the information given influenced the participants' answers to the questionnaires. Since there was no control condition, no statements can be made about the extent to which the information event influenced HCPs' attitudes and perceived normalization.

Due to the high dropout rates at the planned later measurement time, a further investigation of the implementation process was not possible. The reasons for these high drop-out rates can only be speculated. They could indicate a limited implementation success but could also be due to a lack of motivation to additionally participate in such an online survey without reward in a full working life. Furthermore, it would be informative to know how many participants have started using the training. Unfortunately, this information was not available for this study. 


\section{Implications for Future Research}

The identified factors influencing HCPs' normalization of and intention to use novel iCBT interventions might be important in planning future implementation projects and adopting current implementation strategies. However, little is known about effective implementation strategies regarding iCBT (Andersson et al., 2019). The gap between well-evaluated tools and practical use remains. Therefore, experimental studies on the effectiveness of different ideal-typical tailored implementation strategies are needed to foster implementation processes. Despite the HCPs' attitudes seeming to play a central role in normalizing new interventions, the involvement of multiple stakeholders in research (e.g. superiors, supervisors, administrative staff, nursing staff) may be useful to gain a broader view of the whole process and a better understanding of relevant factors influencing early implementation. So far, there is little and partly contradictory evidence on associations between normalization or attitudes towards new interventions with demographic variables such as age, gender, or professional experience (e.g. Aarons et al., 2010; Drozd et al., 2016; Egeland et al., 2016; Titzler et al., 2018). Due to the small, non-representative sample of this study, it was expected that no clarification of this nevertheless important question could be achieved. Future larger studies should therefore examine these relationships more closely so that future implementation concepts can take them into account. Further, attitudes towards interventions and normalization are potentially related to organizational and contextual factors such as culture, organizational structure, and work attitude (Glisson, 2002), which should be also be addressed in future research.

\section{Conclusion}

Internet-based interventions such as the iCBT could improve access to psychotherapeutic and psychiatric care and increase the effectiveness of treatments, but successful and sustainable implementation is the key to the effective use in practice (Aarons \& Palinkas, 2007). The results of this study provide initial indications for the adoption and adaptation of implementation strategies to the needs of service providers. Implementation processes could benefit from tailored information campaigns on the effectiveness and benefits of iCBT interventions to promote openness towards iCBT interventions. Behavioural change interventions to promote normalization processes at the organizational and individual HCP level could increase the acceptance and use of $\mathrm{iCBT}$ interventions.

\section{Appendix}

Regression results
Table 4 Regression results: NoMAD mean as dependent variable

\begin{tabular}{|c|c|c|c|c|c|}
\hline Predictor & $b$ & $\begin{array}{l}b \\
95 \% \text { CI } \\
{[\mathrm{LL}, \mathrm{UL}]}\end{array}$ & $S E$ & $t$ & $p$ \\
\hline $\begin{array}{l}\text { EBPAS organiza- } \\
\text { tional require- } \\
\text { ments }\end{array}$ & -0.06 & {$[-0.12,-0.01]$} & 0.03 & -2.33 & 0.023 \\
\hline $\begin{array}{l}\text { EBPAS intuitive } \\
\text { appeal }\end{array}$ & 0.11 & {$[0.01,0.22]$} & 0.05 & 2.12 & 0.037 \\
\hline EBPAS openness & 0.13 & {$[0.04,0.21]$} & 0.04 & 2.84 & 0.006 \\
\hline EBPAS divergence & 0.47 & {$[0.37,0.57]$} & 0.05 & 9.30 & $<0.001$ \\
\hline
\end{tabular}

$R^{2}=0.636$; adjusted $R^{2}=0.615$. $L L$ and $U L$ indicate the lower and upper limits of a confidence interval $C I$, respectively; $\alpha=0.05$

Table 5 Regression results: NoMAD global score 1 as dependent variable

\begin{tabular}{|c|c|c|c|c|c|}
\hline Predictor & $b$ & $\begin{array}{l}b \\
95 \% \mathrm{CI} \\
{[\mathrm{LL}, \mathrm{UL}]}\end{array}$ & $S E$ & $t$ & $p$ \\
\hline $\begin{array}{l}\text { EBPAS organizational } \\
\text { requirements }\end{array}$ & -2.17 & {$[-5.61,1.27]$} & 0.23 & 1.12 & 0.266 \\
\hline EBPAS intuitive appeal & 0.25 & {$[-0.20,0.71]$} & 0.43 & -0.82 & 0.413 \\
\hline EBPAS openness & -0.36 & {$[-1.22,0.51]$} & 0.36 & 1.11 & 0.270 \\
\hline EBPAS divergence & 0.40 & {$[-0.32,1.12]$} & 0.41 & 3.13 & 0.003 \\
\hline
\end{tabular}

$R^{2}=0.163$; adjusted $R^{2}=0.114 . L L$ and $U L$ indicate the lower and upper limits of a confidence interval $C I$, respectively; $\alpha=0.05$

Table 6 Regression results: NoMAD global score 2 as dependent variable

\begin{tabular}{|c|c|c|c|c|c|}
\hline Predictor & $b$ & $\begin{array}{l}b \\
95 \% \text { CI } \\
{[\mathrm{LL}, \mathrm{UL}]}\end{array}$ & $S E$ & $t$ & $p$ \\
\hline $\begin{array}{l}\text { EBPAS organizational } \\
\text { requirements }\end{array}$ & 0.25 & {$[-0.22,0.72]$} & 0.23 & 1.06 & 0.294 \\
\hline EBPAS intuitive appeal & -0.70 & {$[-1.59,0.19]$} & 0.45 & -1.57 & 0.120 \\
\hline EBPAS openness & 0.45 & {$[-0.29,1.19]$} & 0.37 & 1.22 & 0.226 \\
\hline EBPAS divergence & 1.00 & {$[0.16,1.84]$} & 0.42 & 2.38 & 0.020 \\
\hline
\end{tabular}

$R^{2}=0.125 ;$ adjusted $R^{2}=0.074 . L L$ and $U L$ indicate the lower and upper limits of a confidence interval $C I$, respectively; $\alpha=0.05$

Table 7 Regression results: NoMAD global score 3 as dependent variable

\begin{tabular}{|c|c|c|c|c|c|}
\hline Predictor & $b$ & $\begin{array}{l}b \\
95 \% \mathrm{CI} \\
{[\mathrm{LL}, \mathrm{UL}]}\end{array}$ & $S E$ & $t$ & $p$ \\
\hline $\begin{array}{l}\text { EBPAS organizational } \\
\text { requirements }\end{array}$ & -0.37 & {$[-0.76,0.02]$} & 0.20 & -1.89 & 0.063 \\
\hline EBPAS intuitive appeal & 0.78 & {$[0.04,1.52]$} & 0.37 & 2.09 & 0.040 \\
\hline EBPAS openness & 0.55 & {$[-0.07,1.17]$} & 0.31 & 1.78 & 0.079 \\
\hline EBPAS divergence & 1.02 & {$[0.31,1.72]$} & 0.35 & 2.88 & 0.005 \\
\hline
\end{tabular}

$R^{2}=0.259$; adjusted $R^{2}=0.217$. $L L$ and $U L$ indicate the lower and upper limits of a confidence interval $C I$, respectively; $\alpha=0.05$ 
Table 8 Regression results: NoMAD coherence as dependent variable

\begin{tabular}{|c|c|c|c|c|c|}
\hline Predictor & $b$ & $\begin{array}{l}b \\
95 \% \text { CI } \\
{[\mathrm{LL}, \mathrm{UL}]}\end{array}$ & $S E$ & $t$ & $p$ \\
\hline $\begin{array}{l}\text { EBPAS organiza- } \\
\text { tional require- } \\
\text { ments }\end{array}$ & -0.02 & {$[-0.09,0.05]$} & 0.033 & -0.584 & 0.561 \\
\hline $\begin{array}{l}\text { EBPAS intuitive } \\
\text { appeal }\end{array}$ & 0.12 & {$[-0.00,0.25]$} & 0.062 & 1.974 & 0.052 \\
\hline EBPAS openness & -0.07 & {$[-0.17,0.03]$} & 0.052 & -1.347 & 0.182 \\
\hline $\begin{array}{l}\text { EBPAS diver- } \\
\text { gence }\end{array}$ & 0.69 & {$[0.57,0.81]$} & 0.060 & 11.525 & $<0.001$ \\
\hline
\end{tabular}

$R^{2}=0.668$; adjusted $R^{2}=0.650 . L L$ and $U L$ indicate the lower and upper limits of a confidence interval $C I$, respectively; $\alpha=0.05$

Table 9 Regression results: NoMAD cognitive participation as dependent variable

\begin{tabular}{|c|c|c|c|c|c|}
\hline Predictor & $b$ & $\begin{array}{l}b \\
95 \% \mathrm{CI} \\
{[\mathrm{LL}, \mathrm{UL}]}\end{array}$ & $S E$ & $t$ & $p$ \\
\hline $\begin{array}{l}\text { EBPAS organiza- } \\
\text { tional require- } \\
\text { ments }\end{array}$ & -0.10 & {$[-0.21,-0.00]$} & 0.05 & -2.02 & 0.047 \\
\hline $\begin{array}{l}\text { EBPAS intuitive } \\
\text { appeal }\end{array}$ & 0.14 & {$[-0.05,0.34]$} & 0.10 & 1.48 & 0.143 \\
\hline EBPAS openness & 0.20 & {$[0.04,0.37]$} & 0.08 & 2.51 & 0.014 \\
\hline EBPAS divergence & 0.77 & {$[0.59,0.96]$} & 0.09 & 8.30 & $<0.001$ \\
\hline
\end{tabular}

$R^{2}=0.573$; adjusted $R^{2}=0.550 . L L$ and $U L$ indicate the lower and upper limits of a confidence interval $C I$, respectively; $\alpha=0.05$

Table 10 Regression results: NoMAD collective action as dependent variable

\begin{tabular}{llllll}
\hline Predictor & $b$ & $\begin{array}{l}b \\
95 \% \text { CI } \\
{[\mathrm{LL}, \mathrm{UL}]}\end{array}$ & $S E$ & $t$ & $p$ \\
& & & & \\
\hline $\begin{array}{l}\text { EBPAS organiza- } \\
\text { tional require- } \\
\text { ments }\end{array}$ & -0.02 & {$[-0.10,0.06]$} & 0.040 & -0.523 & 0.603 \\
$\begin{array}{l}\text { EBPAS intuitive } \\
\text { appeal }\end{array}$ & 0.03 & {$[-0.12,0.18]$} & 0.075 & 0.449 & 0.655 \\
$\begin{array}{l}\text { EBPAS openness } \\
\text { EBPAS diver- } \\
\text { gence }\end{array}$ & 0.26 & {$[0.13,0.38]$} & 0.063 & 4.039 & $<0.001$ \\
\hline
\end{tabular}

$R^{2}=0.292$; adjusted $R^{2}=0.252 . L L$ and $U L$ indicate the lower and upper limits of a confidence interval $C I$, respectively; $\alpha=0.05$
Table 11 Regression results: NoMAD reflective monitoring as dependent variable

\begin{tabular}{llllll}
\hline Predictor & $b$ & $\begin{array}{l}b \\
95 \% \text { CI } \\
{[\mathrm{LL}, \mathrm{UL}]}\end{array}$ & SE & \multicolumn{2}{l}{$p$} \\
& & & & & \\
\hline $\begin{array}{l}\text { EBPAS organiza- } \\
\text { tional requirements }\end{array}$ & -0.07 & {$[-0.17,0.02]$} & 0.05 & -1.50 & 0.137 \\
$\begin{array}{l}\text { EBPAS intuitive } \\
\text { appeal }\end{array}$ & 0.11 & {$[-0.08,0.29]$} & 0.09 & 1.17 & 0.245 \\
$\begin{array}{l}\text { EBPAS openness } \\
\text { EBPAS divergence }\end{array}$ & 0.11 & {$[-0.04,0.27]$} & 0.08 & 1.44 & 0.154 \\
\hline
\end{tabular}

$R^{2}=0.288$; adjusted $\mathrm{R}^{2}=0.247 . L L$ and $U L$ indicate the lower and upper limits of a confidence interval $C I$, respectively; $\alpha=0.05$

Funding Open Access funding enabled and organized by Projekt DEAL.

\section{Declarations}

Ethical Considerations Written informed consent was obtained from all participants included in the study. The study was carried out in compliance with the regulations and guidelines established by the German Society for Psychology.

Conflict of Interest Prof. Prof. Ebert reports to have received consultancy fees or served in the scientific advisory board from several companies such as Minddistrict, Sanofi, Lantern, Schön Kliniken, German health insurance companies (BARMER and Techniker Krankenkasse), and chambers of psychotherapists. Dr. Ebert is one of the stakeholders of the Institute for health trainings online (GET.ON Institut für Online Gesundheitstrainings $\mathrm{GmbH}$, HelloBetter), which aims to implement scientific findings related to digital health interventions into routine care. Anne Etzelmueller is employed by the Institute for health trainings online (GET.ON Institut für Online Gesundheitstrainings $\mathrm{GmbH}$, HelloBetter) as research coordinator. All other authors declare that they have no conflict of interest.

Open Access This article is licensed under a Creative Commons Attribution 4.0 International License, which permits use, sharing, adaptation, distribution and reproduction in any medium or format, as long as you give appropriate credit to the original author(s) and the source, provide a link to the Creative Commons licence, and indicate if changes were made. The images or other third party material in this article are included in the article's Creative Commons licence, unless indicated otherwise in a credit line to the material. If material is not included in the article's Creative Commons licence and your intended use is not permitted by statutory regulation or exceeds the permitted use, you will need to obtain permission directly from the copyright holder. To view a copy of this licence, visit http://creativecommons.org/licenses/by/4.0/.

\section{References}

Aarons, G. A. (2004). Mental health provider attitudes toward adoption of evidence-based practice: The Evidence-Based Practice Attitude Scale (EBPAS). Mental Health Services Research, 6(2), 61-74.

Aarons, G. A., Glisson, C., Green, P. D., Hoagwood, K., Kelleher, K. J., \& Landsverk, J. A. (2012a). The organizational social context of mental health services and clinician attitudes toward 
evidence-based practice: A United States national study. Implementation Science, 7(1), 1-15. https://doi.org/10.1186/ 1748-5908-7-56

Aarons, G. A., Glisson, C., Hoagwood, K., Kelleher, K., Landsverk, J., \& Cafri, G. (2010). Psychometric properties and U.S. national norms of the evidence-based practice attitude scale (EBPAS). Psychological Assessment, 22(2), 356-365. https://doi.org/10. 1037/a0019188

Aarons, G. A., Horowitz, J. D., Dlugosz, L. R., \& Ehrhart, M. G. (2012b). The role of organizational processes in dissemination and implementation research. Dissemination and Implementation Research in Health: Translating Science to Practice, 128, 153.

Aarons, G. A., McDonald, E. J., Sheehan, A. K., \& Walrath-Greene, C. M. (2007). Confirmatory factor analysis of the evidence-based practice attitude scale (EBPAS) in a geographically diverse sample of community mental health providers. Administration and Policy in Mental Health and Mental Health Services Research, 34(5), 465-469. https://doi.org/10.1007/s10488-007-0127-x

Aarons, G. A., \& Palinkas, L. A. (2007). Implementation of evidencebased practice in child welfare: Service provider perspectives. Administration and Policy in Mental Health and Mental Health Services Research, 34(4), 411-419. https://doi.org/10.1007/ s10488-007-0121-3

Andersson, G., Titov, N., Dear, B. F., Rozental, A., \& Carlbring, P. (2019). Internet-delivered psychological treatments: From innovation to implementation. World Psychiatry, 18(1), 20-28. https:// doi.org/10.1002/wps. 20610

Arensman, E., Koburger, N., Larkin, C., Karwig, G., Coffey, C., Maxwell, M., Harris, F., Rummel-Kluge, C., van Audenhove, C., Sisask, M., Alexandrova-Karamanova, A., Perez, V., Purebl, G., Cebria, A., Palao, D., Costa, S., Mark, L., Tóth, M. D., Gecheva, M., \& Hegerl, U. (2015). Depression awareness and self-management through the internet: Protocol for an internationally standardized approach. JMIR Research Protocols, 4(3), e99. https://doi.org/10.2196/resprot.4358

Baumeister, H., Terhorst, Y., Grassle, C., Freudenstein, M., Nubling, R., \& Ebert, D. D. (2020). Impact of an acceptance facilitating intervention on psychotherapists' acceptance of blended therapy. PLoS One, 15, 1-15. https://doi.org/10.1371/journal.pone.0236995

Carlbring, P., Andersson, G., Cuijpers, P., Riper, H., \& Hedman-Lagerlöf, E. (2018). Internet-based vs. face-to-face cognitive behavior therapy for psychiatric and somatic disorders: an updated systematic review and meta-analysis. In Cognitive Behaviour Therapy (Vol. 47, Issue 1, pp. 1-18). Routledge. https://doi.org/10.1080/16506073.2017. 1401115

Drozd, F., Vaskinn, L., Bergsund, H. B., Haga, S. M., Slinning, K., \& Bjørkli, C. A. (2016). The implementation of internet interventions for depression: A scoping review. Journal of Medical Internet Research, 18(9), 1-18. https://doi.org/10.2196/jmir.5670

Ebert, D. D., Berking, M., Cuijpers, P., Lehr, D., Pörtner, M., \& Baumeister, H. (2015). Increasing the acceptance of internetbased mental health interventions in primary care patients with depressive symptoms. A randomized controlled trial. Journal of Affective Disorders, 176, 9-17. https://doi.org/10.1016/j.jad.2015. 01.056

Ebert, D. D., Van Daele, T., Nordgreen, T., Karekla, M., Compare, A., Zarbo, C., Brugnera, A., Øverland, S., Trebbi, G., Jensen, K. L., Kaehlke, F., \& Baumeister, H. (2018). Internet- and mobile-based psychological interventions: Applications, efficacy, and potential for improving mental health: A report of the EFPA E-Health Taskforce. In European Psychologist (Vol. 23, Issue 2, pp. 167-187). Hogrefe Publishing. https://doi.org/10.1027/1016-9040/a000318

Egeland, K. M., Ruud, T., Ogden, T., Lindstrøm, J. C., \& Heiervang, K. S. (2016). Psychometric properties of the Norwegian version of the Evidence-Based Practice Attitude Scale (EBPAS): To measure implementation readiness. Health Research Policy and Systems, 14(1), 1-10. https://doi.org/10.1186/s12961-016-0114-3
Etzelmueller, A., Vis, C., Karyotaki, E., Baumeister, H., Titov, N., Berking, M., Cuijpers, P., Riper, H., \& Ebert, D. D. (2020). Effects of Internet-based cognitive behavioral therapy in routine care for adults in treatment for depression and anxiety: Systematic review and meta-analysis. Journal of Medical Internet Research, 22(8), e18100. https://doi.org/10.2196/18100

Finch, T. L., Girling, M., May, C., Mair, F. S., Murray, E., Treweek, S., McColl, E., Steen, I. N., Cook, C., Vernazza, C. R., Mackintosh, N., Sharma, S., Barbery, G., Steele, J., \& Rapley, T. (2018). Improving the normalization of complex interventions: Part 2 - Validation of the NoMAD instrument for assessing implementation work based on normalization process theory (NPT) 17 Psychology and Cognitive Sciences 1701 Psychology. BMC Medical Research Methodology, 18(1), 1-13. https://doi.org/10. 1186/s12874-018-0591-x

Finch, T. L., Rapley, T., Girling, M., Mair, F. S., Murray, E., Treweek, S., Mccoll, E., Steen, I. N., \& May, C. (2013). (2013) Finch et al Improving the normalization of complex interventions. 1-8. https:// doi.org/10.1186/1748-5908-8-43

Frantz, I., \& Heinrichs, N. (2015). Implementation von in der Forschung untersuchten Präventionsprogrammen in die Praxis: Akzeptanz und Barrieren. Zeitschrift Fur Klinische Psychologie Und Psychotherapie, 44(1), 56-61. https://doi.org/10.1026/16163443/a000289

Glisson, C. (2002). The organizational context of children's mental health services. Clinical Child and Family Psychology Review, 5(4), 233-253. https://doi.org/10.1023/A:1020972906177

Gun, S. Y., Titov, N., \& Andrews, G. (2011). Acceptability of internet treatment of anxiety and depression. Australasian Psychiatry, 19(3), 259-264. https://doi.org/10.3109/10398562.2011.562295

Karyotaki, E., Ebert, D. D., Donkin, L., Riper, H., Twisk, J., Burger, S., Rozental, A., Lange, A., Williams, A. D., Zarski, A. C., Geraedts, A., van Straten, A., Kleiboer, A., Meyer, B., Ünlü Ince, B. B., Buntrock, C., Lehr, D., Snoek, F. J., Andrews, G., \& Cuijpers, P. (2018). Do guided internet-based interventions result in clinically relevant changes for patients with depression? An individual participant data meta-analysis. Clinical Psychology Review, 63, 80-92. https://doi.org/10.1016/J.CPR.2018.06.007

Khechine, H., Lakhal, S., \& Ndjambou, P. (2016). A meta-analysis of the UTAUT model: Eleven years later. Canadian Journal of Administrative Sciences, 33(2), 138-152. https://doi.org/10.1002/ cjas. 1381

Königbauer, J., Letsch, J., Doebler, P., Ebert, D. D., \& Baumeister, H. (2017). Internet- and mobile-based depression interventions for people with diagnosed depression: A systematic review and meta-analysis. Journal of Affective Disorders, 223, 28-40. https:// doi.org/10.1016/j.jad.2017.07.021

Mack, S., Jacobi, F., Gerschler, A., Strehle, J., Höfler, M., Busch, M. A., Maske, U. E., Hapke, U., Seiffert, I., Gaebel, W., Zielasek, J., Maier, W., \& Wittchen, H. -U. (2014). Self-reported utilization of mental health services in the adult German population - evidence for unmet needs? Results of the DEGS1-Mental Health Module (DEGS1-MH). International Journal of Methods in Psychiatric Research. https://doi. org/10.1002/mpr.1438

May, C., Cummings, A., Girling, M., Bracher, M., Mair, F. S., May, C. M., Murray, E., Myall, M., Rapley, T., \& Finch, T. (2018). Using normalization process theory in feasibility studies and process evaluations of complex healthcare interventions: A systematic review. Implementation Science. https://doi.org/10.1186/ s13012-018-0758-1

May, C., \& Finch, T. (2009). Implementing, embedding, and integrating practices: An outline of normalization process theory. Sociology, 43(3), 535-554. https://doi.org/10.1177/0038038509103208

McEvoy, R., Ballini, L., Maltoni, S., O’Donnell, C. A., Mair, F. S., \& MacFarlane, A. (2014). A qualitative systematic review of studies using the normalization process theory to research implementation 
processes. Implementation Science, 9(1), 1-13. https://doi.org/10. 1186/1748-5908-9-2

Murray, E., Treweek, S., Pope, C., Macfarlane, A., Ballini, L., Dowrick, C., Finch, T., Kennedy, A., Mair, F., Donnell, C. O., Ong, B. N., Rapley, T., \& Rogers, A. (2010). NPT - a framework for developing evaluating and implementing complex interventions. BMC Medicine.

Oehler, C., Görges, F., Böttger, D., Hug, J., Koburger, N., Kohls, E., \& Rummel-Kluge, C. (2019). Efficacy of an internet-based selfmanagement intervention for depression or dysthymia - A study protocol of an RCT using an active control condition. BMC Psychiatry, 19(1), 1-12. https://doi.org/10.1186/s12888-019-2063-1

Oehler, C., Görges, F., Rogalla, M., Rummel-Kluge, C., \& Hegerl, U. (2020). Efficacy of a guided Web-based self-management intervention for depression or dysthymia: Randomized controlled trial with a 12-month follow-up using an active control condition. Journal of Medical Internet Research, 22(7), e15361. https://doi. org/10.2196/15361

R Core Team. (2019). R: A language and environment for statistical computing (3.5.3). R Foundation for Statistical Computing.

Raftery, J., Kerr, C., Hawker, S., \& Powell, J. (2009). Paying clinicians to join clinical trials: A review of guidelines and interview study of trialists. Trials, 10, 6-11. https://doi.org/10.1186/1745-6215-10-15

Raghavan, R., Bright, C. L., \& Shadoin, A. L. (2008). Toward a policy ecology of implementation of evidence-based practices in public mental health settings. Implementation Science, 3(1), 1-9. https:// doi.org/10.1186/1748-5908-3-26

Rapley, T., Girling, M., Mair, F. S., Murray, E., Treweek, S., McColl, E., Steen, I. N., May, C., \& Finch, T. L. (2018). Improving the normalization of complex interventions: Part 1 - Development of the NoMAD instrument for assessing implementation work based on normalization process theory (NPT) 17 Psychology and Cognitive Sciences 1701 Psychology. BMC Medical Research Methodology, 18(1), 1-17. https://doi.org/10.1186/s12874-018-0590-y

Santesson, A. H. E., Bäckström, M., Holmberg, R., Perrin, S., \& Jarbin, H. (2020). Confirmatory factor analysis of the Evidence-Based Practice Attitude Scale (EBPAS) in a large and representative Swedish sample: Is the use of the total scale and subscale scores justified? BMC Medical Research Methodology, 20(1), 1-12. https://doi.org/10.1186/s12874-020-01126-4

Schnyder, N., Panczak, R., Groth, N., \& Schultze-Lutter, F. (2017). Association between mental health-related stigma and active helpseeking: Systematic review and meta-analysis. British Journal of Psychiatry, 210(4), 261-268. https://doi.org/10.1192/bjp.bp. 116.189464

Terpstra, J. A., van der Vaart, R., Spillekom-van Koulil, S., van Dam, A., Rosmalen, J. G. M., Knoop, H., van Middendorp, H., \& Evers, A. W. M. (2018). Becoming an eCoach: Training therapists in online cognitive-behavioral therapy for chronic pain. Patient Education and Counseling, 101(9), 1702-1707. https://doi.org/ 10.1016/j.pec.2018.03.029

The ImpleMentAll Project. (2020). https://www.implementall.eu/9outcomes-and-resources.html\#NoMADtranslations. Cited 2020, Nov 14
Thornicroft, G., Chatterji, S., Evans-Lacko, S., Gruber, M., Sampson, N., Aguilar-Gaxiola, S., Al-Hamzawi, A., Alonso, J., Andrade, L., \& Borges, G. (2017). Undertreatment of people with major depressive disorder in 21 countries. The British Journal of Psychiatry, 210(2), 119-124.

Titov, N., Hadjistavropoulos, H. D., Nielssen, O., Mohr, D. C., Andersson, G., \& Dear, B. F. (2019). From Research to Practice: Ten Lessons in Delivering Digital Mental Health Services. Journal of Clinical Medicine, 8(8), 1239. https://doi.org/10.3390/ jem8081239

Titzler, I., Saruhanjan, K., Berking, M., Riper, H., \& Ebert, D. D. (2018). Barriers and facilitators for the implementation of blended psychotherapy for depression: A qualitative pilot study of therapists' perspective. Internet Interventions. https://doi.org/10.1016/j. invent.2018.01.002

van Sonsbeek, M. A. M. S., Hutschemaekers, G. J. M., Veerman, J. W., Kleinjan, M., Aarons, G. A., \& Tiemens, B. G. (2015). Psychometric properties of the Dutch version of the Evidence-Based Practice Attitude Scale (EBPAS). Health Research Policy and Systems, 13(1), 1-12. https://doi.org/10.1186/s12961-015-0058-Z

Venkatesh, V., Morris, M. G., Davis, G. B., \& Davis, F. D. (2003). User acceptance of information technology: Toward a unified view. MIS Quarterly, 425-478.

Vis, C., Ruwaard, J., Finch, T., Rapley, T., de Beurs, D., van Stel, H., Van Lettow, B., Mol, M., Kleiboer, A., Riper, H., \& Smit, J. (2019). Toward an objective assessment of implementation processes for innovations in health care: Psychometric evaluation of the normalization Measure Development (NOMAD) questionnaire among mental health care professionals. Journal of Medical Internet Research. https://doi.org/10.2196/12376

Whiteford, H. A., Ferrari, A. J., Degenhardt, L., Feigin, V., \& Vos, T. (2015). The global burden of mental, neurological and substance use disorders: an analysis from the Global Burden of Disease Study 2010. PLoS One, 10(2), e0116820.

Wittchen, H. U., Jacobi, F., Rehm, J., Gustavsson, A., Svensson, M., Jönsson, B., Olesen, J., Allgulander, C., Alonso, J., Faravelli, C., Fratiglioni, L., Jennum, P., Lieb, R., Maercker, A., van Os, J., Preisig, M., Salvador-Carulla, L., Simon, R., \& Steinhausen, H. -C. (2011). The size and burden of mental disorders and other disorders of the brain in Europe 2010. European Neuropsychopharmacology, 21(9), 655-679. https://doi.org/10.1016/J. EURONEURO.2011.07.018

Zachariae, R., Lyby, M. S., Ritterband, L., \& O'Toole, M. S. (2015). Efficacy of Internet-delivered cognitive-behavioral therapy for insomnia - a systematic review and meta-analysis of randomized controlled trials. Sleep Medicine Reviews, 30, 1-10. https://doi. org/10.1016/j.smrv.2015.10.004

Publisher's Note Springer Nature remains neutral with regard to jurisdictional claims in published maps and institutional affiliations. 